\title{
Comparative Studies of Different Switching Patterns for Direct and Indirect Space Vector Modulated Matrix Converter
}

\author{
Amin Shabanpour, Sasan Gholami, and Ali Reza Seifi \\ School of Electrical and Computer Engineering, Shiraz University, Shiraz 71345, Iran \\ Correspondence should be addressed to Ali Reza Seifi, seifi@shirazu.ac.ir \\ Received 17 May 2012; Accepted 17 November 2012 \\ Academic Editor: Francesco Profumo
}

Copyright ( $) 2012$ Amin Shabanpour et al. This is an open access article distributed under the Creative Commons Attribution License, which permits unrestricted use, distribution, and reproduction in any medium, provided the original work is properly cited.

This paper presents a MATLAB/Simulink simulation of direct and indirect space vector modulation for matrix converter. Different switching patterns for both direct and indirect methods are simulated and compared. Three criteria are chosen to compare the performance of switching patterns: (1) total harmonic distortion (THD); (2) harmonic spectrum analysis of output voltages; and (3) number of switching in each switching period. Switching strategies are completely implemented using the power library in MATLAB/Simulink environment.

\section{Introduction}

Three-phase matrix converter is an AC-to-AC converter with nine bidirectional switches. These switches are organized in a $3 \times 3$ matrix and with this arrangement any output phase can be connected to any input phase [1]. Some advantages of using this converter are providing bidirectional power flow; control of output waveforms and input power factor; and absence of DC capacitor [2]. Different approaches for switching of matrix converter have been proposed in literatures [2-6]. Many aspects such as output harmonic spectrum, total harmonic distortion (THD), complexity of implementation, and number of switching play important roles in determination of an appropriate modulation strategy. Space vector modulation has been successively improved in recent years and is considered as a standard technique in matrix converter modulations $[2,5]$. Despite the fact that this concept is presented in various literatures, it is still ambiguous for engineers to completely comprehend its operating principle.

Space vector switching methods for matrix converter are classified into two different strategies: (1) indirect space vector modulation which takes the advantage of a virtual $\mathrm{dc}$ link [5] and ((2) direct space vector modulation that provides direct conversion [2]. So far only one comparison between the direct and indirect space vector modulation is reported
[7]. In [7] the direct and indirect control performances of a matrix converter supplying an induction motor (IM) have been carried out; however, different switching patterns are not investigated.

In this paper first the two methods of indirect and direct space vector modulation of matrix converter are reviewed. Then different switching patterns are introduced, and each switching pattern will be simulated in MATLAB/Simulink software. Simulations and comparison are done under the same conditions of the input power supply and the output load. In order to compare the performances of switching patterns three criteria are considered: total harmonic distortion, harmonic analysis of output voltage, and number of switching. The rest of the paper is as follows: Section 2 explores the matrix converter fundamental. Sections 3 and 4 describe the indirect and direct space vector modulations, respectively. The switching patterns are given in Section 5. In Section 6 simulation results are discussed. Finally the conclusion is given.

\section{Matrix Converter}

The $3 \phi-3 \phi$ matrix converter scheme is shown in Figure 1 . matrix converter comprises of nine bidirectional switches so arranged that any of the three output phases can be 


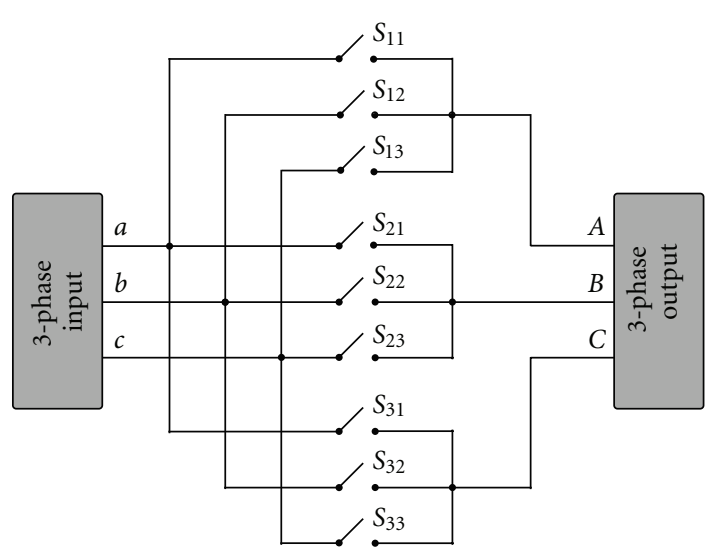

FIgURE 1: Direct matrix converter.

connected to any input phase. Bidirectional switches make it possible to connect any of input phases $a, b$, or $c$ to any of output phases $A, B$, or $C$ at any moment. The input phases of matrix converter must not be shorted due to the input voltage sources, and the output phases must not be opened due to the inductive nature of the load. The switch function, $S_{\alpha \beta}$, can be defined as

$$
\begin{aligned}
S_{\alpha \beta}= \begin{cases}0 & S_{\alpha \beta}: \text { open, } \\
1 & S_{\alpha \beta}: \text { close, }\end{cases} \\
\quad \alpha \in\{a, b, c\}, \beta \in\{A, B, C\} .
\end{aligned}
$$

The restriction is expressed as

$$
S_{a \beta}+S_{b \beta}+S_{c \beta}=1
$$

The output voltages and input currents of the matrix converter can be represented by the switching function $S$ and the transposed $S^{T}$, such as

$$
\begin{gathered}
{\left[V_{\text {out }}\right]=[S] \times\left[V_{\text {in }}\right],} \\
{\left[\begin{array}{c}
V_{A} \\
V_{B} \\
V_{C}
\end{array}\right]=\left[\begin{array}{lll}
S_{11} & S_{21} & S_{31} \\
S_{12} & S_{22} & S_{32} \\
S_{13} & S_{23} & S_{33}
\end{array}\right] \cdot\left[\begin{array}{c}
V_{a} \\
V_{b} \\
V_{c}
\end{array}\right],} \\
{\left[I_{\text {in }}\right]=\left[\begin{array}{l}
S^{T}
\end{array}\right] \times\left[I_{\text {out }}\right],} \\
{\left[\begin{array}{c}
I_{a} \\
I_{b} \\
I_{c}
\end{array}\right]=\left[\begin{array}{lll}
S_{11} & S_{12} & S_{13} \\
S_{21} & S_{22} & S_{23} \\
S_{31} & S_{32} & S_{33}
\end{array}\right] \cdot\left[\begin{array}{c}
I_{A} \\
I_{B} \\
I_{C}
\end{array}\right],}
\end{gathered}
$$

where $V_{a}, V_{b}$, and $V_{c}$ are input phase voltages; $V_{A}, V_{B}$ and $V_{C}$ are output phase voltages; $I_{a}, I_{b}$, and $I_{c}$ are input currents; $I_{A}, I_{B}$, and $I_{C}$ are output currents.

\section{Indirect Space Vector Modulation}

A space vector is obtained from three phase quantities through the following transformation:

$$
\begin{gathered}
\vec{X}=\frac{2}{3}\left(\chi_{a}+\bar{\alpha} \chi_{b}+\bar{\alpha}^{2} \chi_{c}\right), \\
\bar{\alpha}=e^{j(2 \pi / 3)}=\cos \left(\frac{2 \pi}{3}\right)+j \sin \left(\frac{2 \pi}{3}\right) .
\end{gathered}
$$

Many engineers are familiar with the space vector modulation (SVM) for voltage source inverters (VSIs) [8]; however, the modulation method for the matrix converter is understood to few engineers due to the high level of intricacy and limited materials to explain its fundamentals. Hence, it would be easier and more conceivable to illustrate the switching operation of matrix converter by adopting conventional VSI topology and SVM concept. The indirect space vector modulation (indirect SVM) was first proposed by Huber and Borojevic. [5], where matrix converter was described to an equivalent circuit consisting of current source rectifier and voltage source inverter connected through virtual dc link as shown in Figure 2. The idea of the indirect modulation technique is to separate the control of the input current and output voltage.

This is done by dividing the switching function $S$ into the product of a rectifier and an inverter switching function:

$$
\begin{gathered}
{\left[\begin{array}{lll}
S_{11} & S_{21} & S_{31} \\
S_{12} & S_{22} & S_{32} \\
S_{13} & S_{23} & S_{33}
\end{array}\right]=\left[\begin{array}{ll}
S_{7} & S_{8} \\
S_{9} & S_{10} \\
S_{11} & S_{12}
\end{array}\right] \cdot\left[\begin{array}{lll}
S_{1} & S_{3} & S_{5} \\
S_{2} & S_{4} & S_{6}
\end{array}\right],} \\
{\left[\begin{array}{l}
V_{A} \\
V_{B} \\
V_{C}
\end{array}\right]=\left[\begin{array}{ll}
S_{7} & S_{8} \\
S_{9} & S_{10} \\
S_{11} & S_{12}
\end{array}\right] \cdot\left[\begin{array}{lll}
S_{1} & S_{3} & S_{5} \\
S_{2} & S_{4} & S_{6}
\end{array}\right] \cdot\left[\begin{array}{l}
V_{a} \\
V_{b} \\
V_{c}
\end{array}\right] .}
\end{gathered}
$$

So the space vector for the two voltage source converters shown in Figure 2 can be applied to the matrix converter shown in Figure 1. For example $S_{1} \cdot S_{7}+S_{8} \cdot S_{2}$ in Figure 2 is equivalent to $S_{11}$ in Figure 1. Two space vector modulations for current source rectifier and voltage source inverter stages should be implemented, and then the two modulation results should be combined.

\section{Space Vector Modulation for the Rectifier Stage}

The rectifier part of the equivalent circuit can be assumed as a current source rectifier (CSR) with the averaged value of $I_{\mathrm{DC}}$ and is derived as follows:

$$
I_{\mathrm{DC}}=\frac{\sqrt{3}}{2} I_{\text {out }} \cdot m_{v} \cdot \cos \left(\theta_{\text {out }}\right) .
$$

$I_{\text {out }}$ is the peak value of output current, $\theta_{\text {out }}$ is the output load displacement angle, and $m_{v}=V_{\text {out }} / V_{\mathrm{DC}}$. The input current space vector $I_{\text {ref }}$ is extracted as follows:

$$
I_{\text {ref }}=\frac{2}{3}\left(I_{a}+\bar{\alpha} I_{b}+\bar{\alpha}^{2} I_{c}\right) .
$$




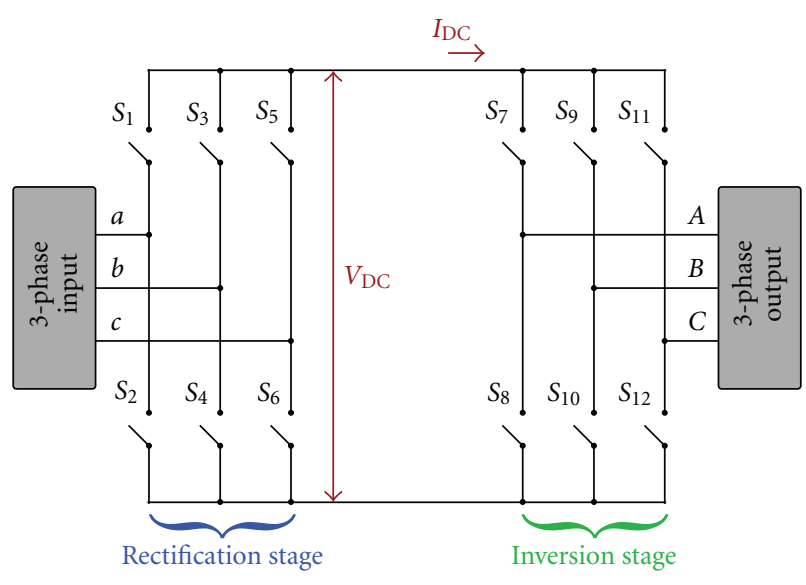

Figure 2: Indirect matrix converter.

The nine rectifier switches have nine permitted combinations to avoid an open circuit at the dc link. These combinations include three zero and six nonzero input currents given in Table 1 .

The reference input current vector is synthesized by impressing the adjoining switching vectors $\left(I_{\gamma}\right)$ and $\left(I_{\delta}\right)$ with duty cycles $\left(d_{\gamma}\right)$ and $\left(d_{\delta}\right)$, respectively. The reference vector can be expressed by the current-time product sum of the adjoining active vectors as illustrated in Figure 3:

$$
I_{\mathrm{ref}}=d_{\gamma} \cdot I_{\gamma}+d_{\delta} \cdot I_{\delta}
$$

The duty cycle of the active vectors are calculated by

$$
\begin{gathered}
d_{\gamma}=\frac{T_{\gamma}}{T_{s}}=m_{c} \sin \left(\frac{\pi}{3}-\theta_{i}\right), \\
d_{\delta}=\frac{T_{\delta}}{T_{s}}=m_{c} \sin \left(\theta_{i}\right), \\
d_{\mathrm{oc}}=\frac{T_{\mathrm{oc}}}{T_{s}}=1-d_{\delta}-d_{\gamma},
\end{gathered}
$$

where $\theta_{i}$ indicates the angle of the reference current vector. The current modulation index, $m_{c}$, defines the desired current transfer ratio such as

$$
m_{c}=\frac{I_{\mathrm{ref}}}{I_{\mathrm{DC}}} ; \quad 0 \leq m_{c} \leq 1 .
$$

\section{Space Vector Modulation for the Inverter Stage}

The inverter can be assumed as a separate VSI. The switching method is exactly similar to conventional VSI [8], but owing to its virtual DC link, $V_{\mathrm{DC}}$ should be defined as follows:

$$
V_{\mathrm{DC}}=\frac{3}{2} V_{\mathrm{in}} \cdot m_{c} \cdot \cos \left(\theta_{\mathrm{in}}\right) .
$$

$V_{\text {in }}$ is the peak value of input voltage, and $\theta_{\text {in }}$ is the input displacement angle.

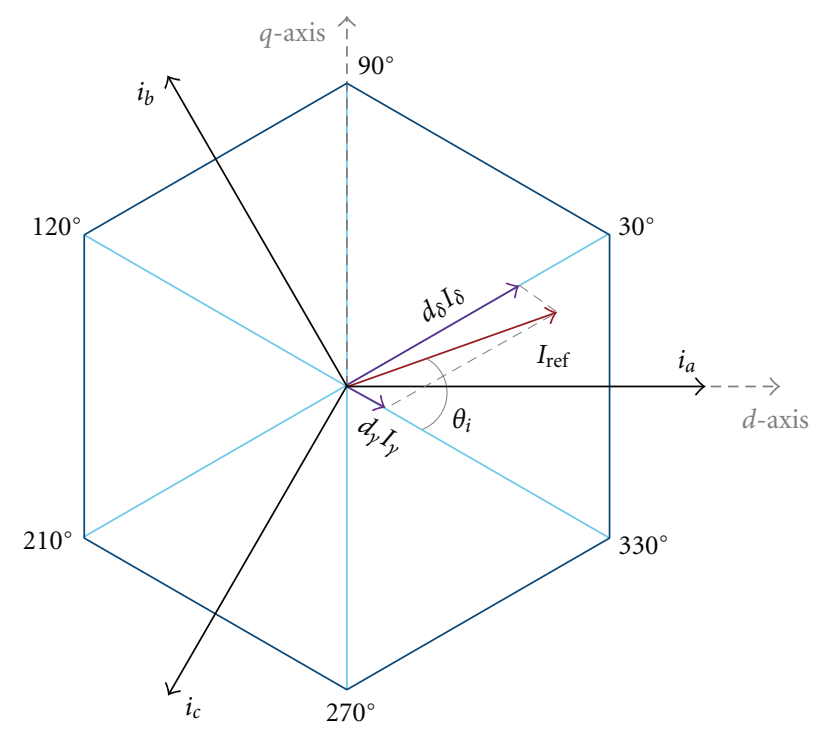

FIGURE 3: Input current space vector in complex plane.

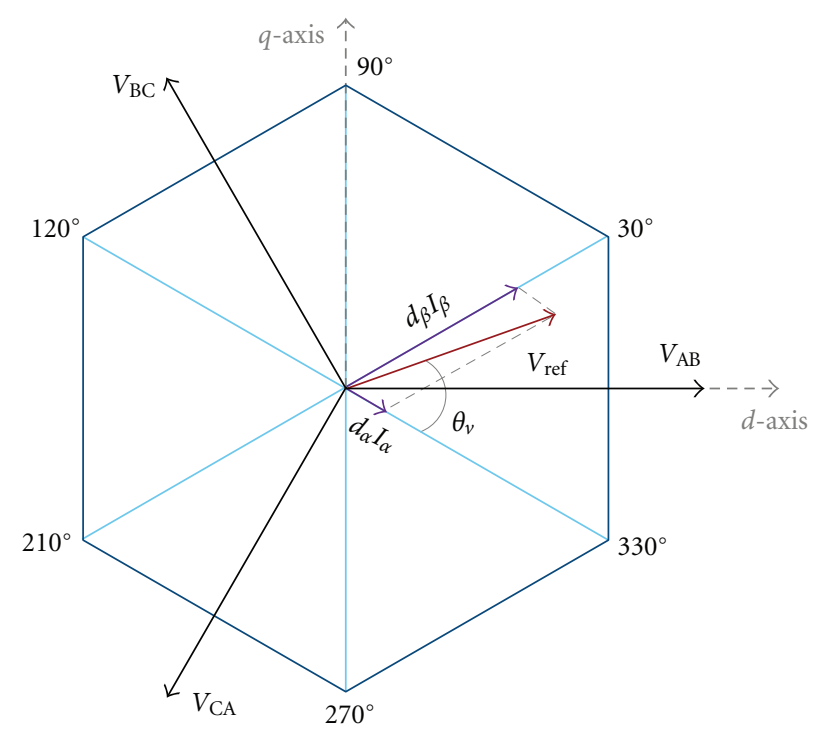

FIgURE 4: Output voltage space vector in complex plane.

The output voltage space vector, $V_{\text {ref }}$, is evaluated as.

$$
V_{\text {ref }}=\frac{2}{3}\left(V_{a}+\bar{\alpha} V_{b}+\bar{\alpha}^{2} V_{c}\right) .
$$

The inverter switches have eight permitted combinations to avoid a short circuit. These combinations include three zero and six nonzero input currents (see Table 2).

The reference output voltage vector is synthesized by impressing the adjoining active vectors $V_{\alpha}$ and $V_{\beta}$ with the duty cycles $d_{\alpha}$ and $d_{\beta}$, respectively. The reference vector can be expressed by the voltage-time product sum of the adjoining active vectors as illustrated in Figure 4:

$$
V_{\text {ref }}=d_{\alpha} \cdot V_{\alpha}+d_{\beta} \cdot V_{\beta} \text {. }
$$


TABLE 1: Current vectors for rectifier stage.

\begin{tabular}{|c|c|c|c|c|c|c|c|c|}
\hline Type & Vector & $I_{\mathrm{ref}}$ & $\mathrm{S}_{1}$ & $\mathrm{~S}_{2}$ & $\mathrm{~S}_{3}$ & $\mathrm{~S}_{4}$ & $\mathrm{~S}_{5}$ & $\mathrm{~S}_{6}$ \\
\hline \multirow{6}{*}{ Active } & $I_{1}$ & $2 / \sqrt{3} I_{\mathrm{DC}}<-\pi / 6$ & 1 & 0 & 0 & 1 & 0 & 0 \\
\hline & $I_{2}$ & $2 / \sqrt{3} I_{\mathrm{DC}}<\pi / 6$ & 1 & 0 & 0 & 0 & 0 & 1 \\
\hline & $I_{3}$ & $2 / \sqrt{3} I_{\mathrm{DC}}<\pi / 2$ & 0 & 0 & 1 & 0 & 0 & 1 \\
\hline & $I_{4}$ & $2 / \sqrt{3} I_{\mathrm{DC}}<5 \pi / 6$ & 0 & 1 & 1 & 0 & 0 & 0 \\
\hline & $I_{5}$ & $2 / \sqrt{3} I_{\mathrm{DC}}<-5 \pi / 6$ & 0 & 1 & 0 & 0 & 1 & 0 \\
\hline & $I_{6}$ & $2 / \sqrt{3} I_{\mathrm{DC}}<-\pi / 2$ & 0 & 0 & 0 & 1 & 1 & 0 \\
\hline \multirow{3}{*}{ Zero } & & & 1 & 1 & 0 & 0 & 0 & 0 \\
\hline & $I_{0}$ & 0 & 0 & 0 & 1 & 1 & 0 & 0 \\
\hline & & & 0 & 0 & 0 & 0 & 1 & 1 \\
\hline
\end{tabular}

TABLE 2: Voltage vectors for inverter stage.

\begin{tabular}{|c|c|c|c|c|c|c|c|c|}
\hline Type & Vector & $V_{\text {ref }}$ & $\mathrm{S}_{7}$ & $\mathrm{~S}_{8}$ & $\mathrm{~S}_{9}$ & $\mathrm{~S}_{10}$ & $S_{11}$ & $\mathrm{~S}_{12}$ \\
\hline \multirow{6}{*}{ Active } & $V_{1}$ & $2 / 3 V_{\mathrm{DC}}<0$ & 1 & 0 & 0 & 1 & 0 & 1 \\
\hline & $V_{2}$ & $2 / 3 V_{\mathrm{DC}}<\pi / 3$ & 1 & 0 & 1 & 0 & 0 & 1 \\
\hline & $V_{3}$ & $2 / 3 V_{\mathrm{DC}}<2 \pi / 3$ & 0 & 1 & 1 & 0 & 0 & 1 \\
\hline & $V_{4}$ & $2 / 3 V_{\mathrm{DC}}<\pi$ & 0 & 1 & 1 & 0 & 1 & 0 \\
\hline & $V_{5}$ & $2 / 3 V_{\mathrm{DC}}<-2 \pi / 3$ & 0 & 1 & 0 & 1 & 1 & 0 \\
\hline & $V_{6}$ & $2 / 3 V_{\mathrm{DC}}<-\pi / 3$ & 1 & 0 & 0 & 1 & 1 & 0 \\
\hline \multirow{2}{*}{ Zero } & \multirow{2}{*}{$V_{0}$} & \multirow{2}{*}{0} & 1 & 0 & 1 & 0 & 1 & 0 \\
\hline & & & 0 & 1 & 0 & 1 & 0 & 1 \\
\hline
\end{tabular}

The duty cycles of the active vectors can be written as:

$$
\begin{gathered}
d_{\alpha}=\frac{T_{\alpha}}{T_{s}}=m_{v} \sin \left(\frac{\pi}{3}-\theta_{v}\right), \\
d_{\beta}=\frac{T_{\beta}}{T_{s}}=m_{v} \sin \left(\theta_{v}\right), \\
d_{\mathrm{ov}}=\frac{T_{\mathrm{ov}}}{T_{s}}=1-d_{\alpha}-d_{\beta},
\end{gathered}
$$

where $\theta_{v}$ indicates the angle of the reference voltage vector. $m_{v}$ is the voltage modulation index and defines the desired voltage transfer ratio such as

$$
m_{v}=\frac{\sqrt{3} V_{\mathrm{ref}}}{V_{\mathrm{DC}}} ; \quad 0 \leq m_{v} \leq 1,
$$

\section{Direct Space Vector Modulation}

In direct space vector modulation the actual matrix converter circuit is considered without any assumption of an equivalent circuit. For operation of the matrix converter one and only one switch in each output phase must be conducting. This leads to twenty-seven possible switching combinations for the matrix converter. Modulation is more complicated because these vectors vary continuously and depend on instantaneous magnitude of sources. The output voltage states are usually classified in three groups:

(i) 18 combinations with fixed directions,

(ii) 3 zero vectors,

(iii) 6 rotating vectors.
The 6 combinations of rotating vectors in group 3 are not used. Similar to indirect space vector modulation the reference output voltage vector is synthesized by impressing the adjoining active vectors. The reference input current vector is also synthesized by impressing the adjoining switching current vectors. Figure 5 shows the output voltage and input current reference space vectors. For any combination of output voltage and input current sectors, four configurations can be identified, which produce output voltage and input current vectors. Among the switching that can be selected in each sector, ones that are shared input current and output voltage vectors are used. Table 3 shows the possible configurations. Duty cycle calculations are given in [2]. If $k_{v}$ and $k_{i}$ are the sectors where $V_{\text {ref }}$ and $I_{\text {ref }}$ are placed and $\alpha$ and $\beta$ are the phase angles within the sectors $V_{\text {ref }}$ and $I_{\text {ref, }}$, the duty cycles are calculated by

$$
\begin{gathered}
T_{1}=(-1)^{k_{v}+k_{i}} \frac{2}{\sqrt{3}} q \frac{\cos (\alpha-\pi / 3) \cos (\beta-\pi / 3)}{\cos \left(\varphi_{i}\right)}, \\
T_{2}=(-1)^{k_{v}+k_{i}+1} \frac{2}{\sqrt{3}} q \frac{\cos (\alpha-\pi / 3) \cos (\beta+\pi / 3)}{\cos \left(\varphi_{i}\right)}, \\
T_{3}=(-1)^{k_{v}+k_{i}+1} \frac{2}{\sqrt{3}} q \frac{\cos (\alpha+\pi / 3) \cos (\beta-\pi / 3)}{\cos \left(\varphi_{i}\right)}, \\
T_{4}=(-1)^{k_{v}+k_{i}} \frac{2}{\sqrt{3}} q \frac{\cos (\alpha+\pi / 3) \cos (\beta+\pi / 3)}{\cos \left(\varphi_{i}\right)}, \\
T_{0}=1-T_{1}-T_{2}-T_{3}-T_{4} .
\end{gathered}
$$




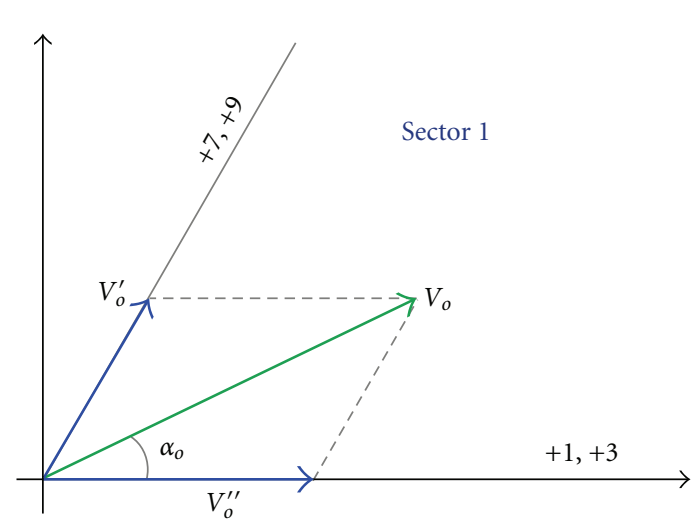

(a)

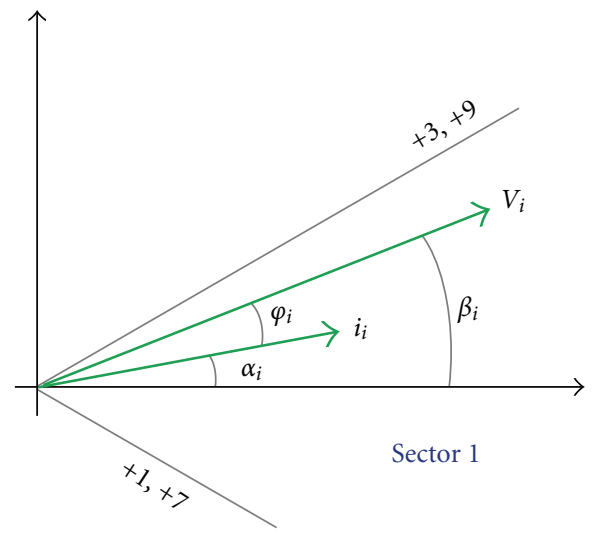

(b)

FIgURE 5: The output voltage and input current reference space vectors.

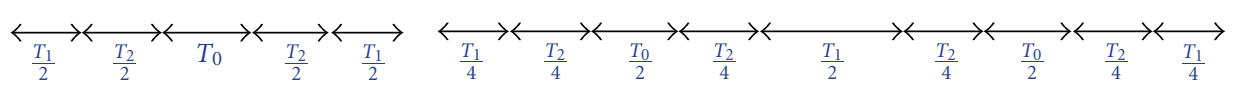

(a)

(b)

FIGURE 6: Switching patterns for indirect modulation: (a) single sided; (b) double sided.

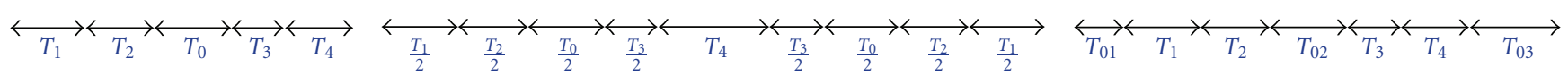

(a)

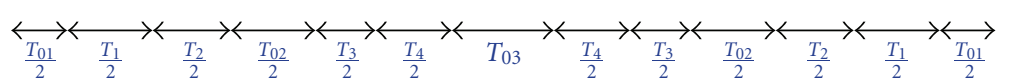

(d)

FIGURE 7: Switching patterns for direct modualation: (a) asymmetrical single sided; (b) asymmetrical double sided; (c) symmetrical single sided; (d) symmetrical double sided.
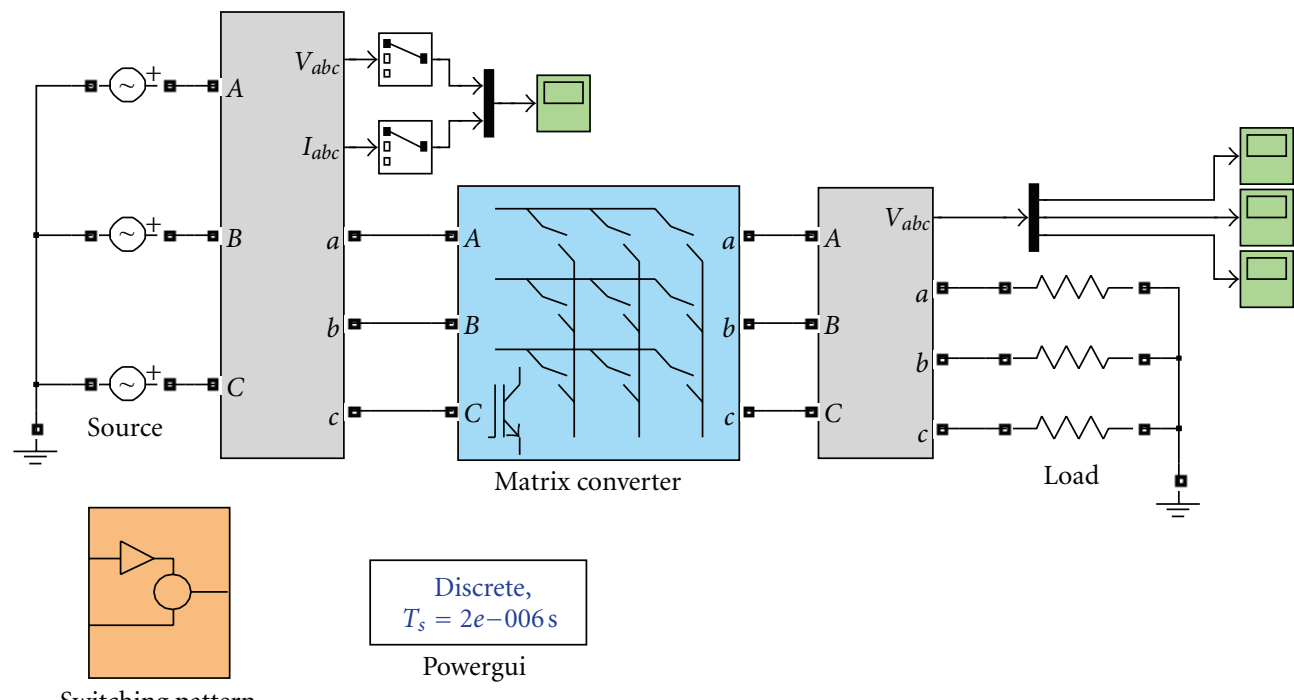

Switching pattern generator

FIgURE 8: Test case schematic in Matlab/Simulink. 
TABLE 3: Switching configurations.

\begin{tabular}{|c|c|c|}
\hline Switches on & $V_{o}$ & $I_{o}$ \\
\hline $1,5,6$ & $2 / 3 V_{A B}<0$ & $2 / \sqrt{3} i_{a}<-\pi / 6$ \\
\hline $4,2,3$ & $-2 / 3 V_{A B}<0$ & $-2 / \sqrt{3} i_{a}<-\pi / 6$ \\
\hline $4,8,9$ & $2 / 3 V_{B C}<0$ & $2 / \sqrt{3} i_{a}<\pi / 2$ \\
\hline $7,5,6$ & $-2 / 3 V_{B C}<0$ & $-2 / \sqrt{3} i_{a}<\pi / 2$ \\
\hline $7,2,3$ & $2 / 3 V_{C A}<0$ & $2 / \sqrt{3} i_{a}<7 \pi / 6$ \\
\hline $1,8,9$ & $-2 / 3 V_{C A}<0$ & $-2 / \sqrt{3} i_{a}<7 \pi / 6$ \\
\hline $4,2,6$ & $2 / 3 V_{A B}<2 \pi / 3$ & $2 / \sqrt{3} i_{b}<-\pi / 6$ \\
\hline $1,5,3$ & $-2 / 3 V_{A B}<2 \pi / 3$ & $-2 / \sqrt{3} i_{b}<-\pi / 6$ \\
\hline $4,5,9$ & $2 / 3 V_{B C}<2 \pi / 3$ & $2 / \sqrt{3} i_{b}<\pi / 2$ \\
\hline $4,8,6$ & $-2 / 3 V_{B C}<2 \pi / 3$ & $-2 / \sqrt{3} i_{b}<\pi / 2$ \\
\hline $1,8,3$ & $2 / 3 V_{C A}<2 \pi / 3$ & $2 / \sqrt{3} i_{b}<7 \pi / 6$ \\
\hline $7,2,9$ & $-2 / 3 V_{C A}<2 \pi / 3$ & $-2 / \sqrt{3} i_{b}<7 \pi / 6$ \\
\hline $4,5,3$ & $2 / 3 V_{A B}<4 \pi / 3$ & $2 / \sqrt{3} i_{b}<-\pi / 6$ \\
\hline $1,2,6$ & $-2 / 3 V_{A B}<4 \pi / 3$ & $-2 / \sqrt{3} i_{c}<-\pi / 6$ \\
\hline $7,8,6$ & $2 / 3 V_{B C}<4 \pi / 3$ & $2 / \sqrt{3} i_{c}<\pi / 2$ \\
\hline $4,5,9$ & $-2 / 3 V_{B C}<4 \pi / 3$ & $-2 / \sqrt{3} i_{c}<\pi / 2$ \\
\hline $1,2,9$ & $2 / 3 V_{C A}<4 \pi / 3$ & $2 / \sqrt{3} i_{c}<7 \pi / 6$ \\
\hline $7,8,3$ & $-2 / 3 V_{C A}<4 \pi / 3$ & $-2 / \sqrt{3} i_{c}<7 \pi / 6$ \\
\hline $1,2,3$ & 0 & 0 \\
\hline $4,5,6$ & 0 & 0 \\
\hline $7,8,9$ & 0 & 0 \\
\hline
\end{tabular}

TABle 4: Test case system parameters.

\begin{tabular}{lc}
\hline Parameter & Value \\
\hline Source voltage (peak) & $100 \mathrm{~V}$ \\
System frequency & $60 \mathrm{~Hz}$ \\
Load resistance & $5 \Omega$ \\
Switching frequency & $6 \mathrm{kHz}$ \\
Modulation index & 0.8 \\
Sampling time & $2 \mu \mathrm{s}$ \\
\hline
\end{tabular}

In these equations $\varphi_{i}$ is the displacement angle between current space vectors and input voltage space vectors, and $q=V_{o} / V_{i}$ is the voltage ratio.

\section{Switching Pattern}

The order in which the vectors are placed along one period is called switching pattern.

A proper choice of the switching pattern should be applied to the switches of the matrix converter in order to achieve the desired output. There are different combinations for ordering the time segments corresponding to duty ratios. In this paper two switching patterns are considered for indirect space vector modulation. A single and a double distributions of time periods during a switching period are selected. These patterns are shown in Figure 6.

Four switching patterns are simulated and analyzed for direct space vector modulation: (1) asymmetrical single sided, which uses only one of the three zero vectors; (2)
TABLE 5: Simulation results.

\begin{tabular}{lcc}
\hline Pattern & THD\% & $\begin{array}{c}\text { Number of } \\
\text { Switching for } \\
\text { each switch }\end{array}$ \\
\hline Single side indirect & 69.59 & 88 \\
Double side indirect & 68.15 & 159 \\
Asymmetrical single side direct & 70.84 & 62 \\
Asymmetrical double side direct & 66.92 & 163 \\
Symmetrical single side direct & 67.21 & 130 \\
Symmetrical double side direct & 65.32 & 192 \\
\hline
\end{tabular}

asymmetrical double sided switching pattern; (3) symmetrical single sided, which utilizes all the three zero vectors and (4) symmetrical double-sided pattern. Figure 7 shows these switching patterns.

\section{Simulation Results}

In order to compare the performances of the direct and indirect space vector modulation techniques, these methods are applied to an AC/AC matrix converter. This system consists of a simple source voltage that is connected to a resistive load through a matrix converter. The simulations were performed with Matlab/Simulink software as shown in Figure 8. The main circuits were assumed to be ideal, and results are evaluated under the same conditions for the input power supply and the output Load. The parameters of the system are shown in Table 4 . Two patterns of Figure 6 and four patterns of Figure 7 are simulated. Table 5 compares 


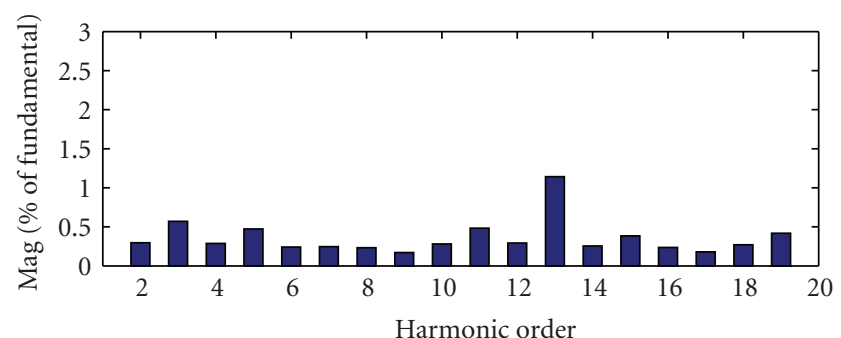

(a)

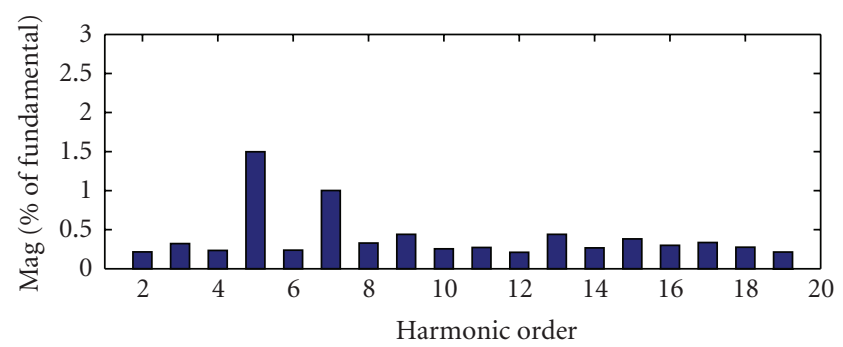

(c)

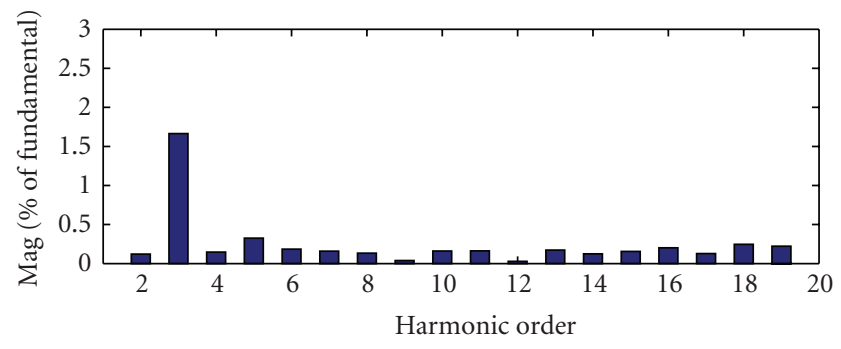

(e)

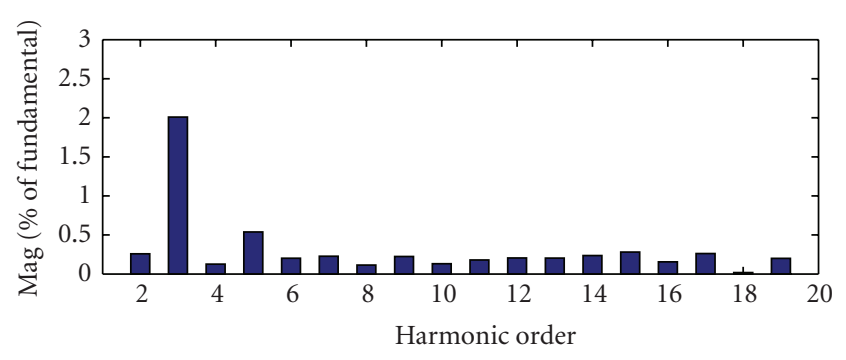

(b)

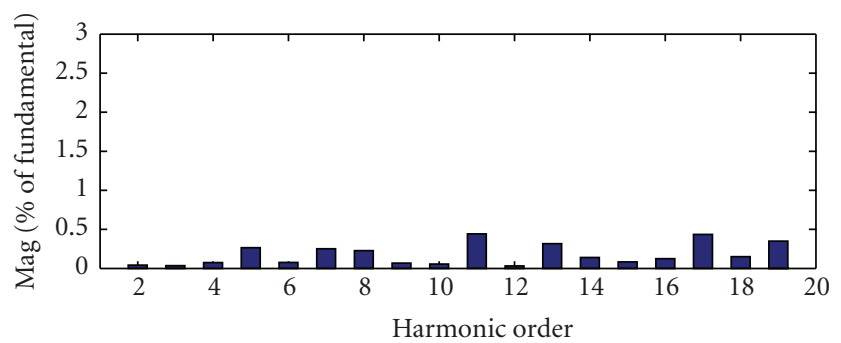

(d)

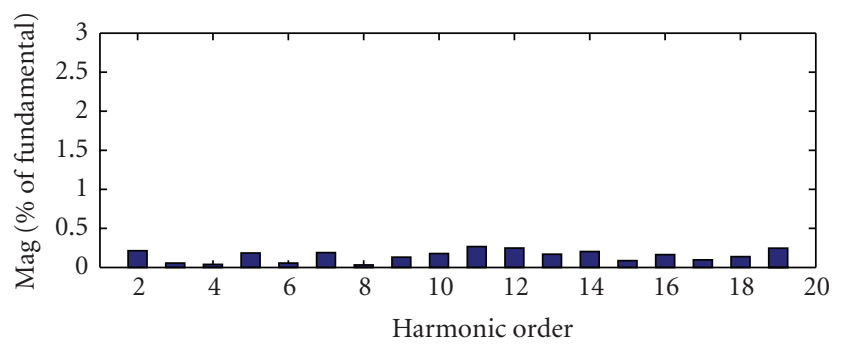

(f)

Figure 9: Harmonic spectrum of output voltage: (a) single side indirect; (b) double side indirect; (c) asymmetrical single side direct; (d) asymmetrical double side direct; (e) symmetrical single side direct; (f) symmetrical double side direct.

THD and the number of switching in each switching period for these methods. Furthermore, Figure 9 illustrates harmonic spectrum of output voltage for the six patterns. As the higher harmonics could be removed easily by a low-pass filter, Figure 9 only shows the low-order harmonics, which are harder to be eliminated. However, the THDs of Table 5 all consist of the harmonics.

Based on these simulation results, the double-sided patterns show the following characteristics over the singlesided pattern:

(i) lower harmonic distortion,

(ii) greater number of switching.

In addition, the analysis for symmetrical and asymmetrical patterns shows that the symmetrical pattern is more appropriate choice for a lower harmonic distortion in spite of greater switching losses.

\section{Conclusion}

This paper compares different switching patterns of direct and indirect space vector modulations for three-phase matrix converter. Two methods of indirect and direct space vector modulation of matrix converter were completely described. Double-sided and single-sided patterns as well as symmetrical and asymmetrical patterns were analyzed in Simulink. Comparison results were evaluated based on three criteria: (1) total harmonic distortion (THD); (2) harmonic spectrum analysis of output voltages; and (3) number of switching in each switching period. As expected the double-sided as well as symmetrical patterns produces lower harmonic distortions. However, the number of switching increases when using double-sided and symmetrical patterns.

\section{References}

[1] P. W. Wheeler, J. Rodríguez, J. C. Clare, M. L. Empringham, and A. Weinstein, "Matrix converters: a technology review," IEEE Transactions on Industrial Electronics, vol. 49, no. 2, pp. 276288, 2002.

[2] D. Casadei, G. Serra, A. Tani, and L. Zarri, "Matrix converter modulation strategies: a new general approach based on spacevector representation of the switch state," IEEE Transactions on Industrial Electronics, vol. 49, no. 2, pp. 370-381, 2002.

[3] M. Venturini and A. Alesina, "Generalised transformer: a new bidirectional, sinusoidal waveform frequency converter with 
continuously adjustable input power factor," in Proceedings of the IEEE Power Electronics Specialists Conference (PESC '80), pp. 242-252, Atlanta, Ga, USA, June 1980.

[4] A. Alesina and M. G. B. Venturini, "Analysis and design of optimum-amplitude nine-switch direct AC-AC converters," IEEE Transactions on Power Electronics, vol. 4, no. 1, pp. 101$112,1989$.

[5] L. Huber and D. Borojevic, "Space vector modulated threephase to three-phase matrix converter with input power factor correction," IEEE Transactions on Industry Applications, vol. 31, no. 6, pp. 1234-1246, 1995.

[6] J. Rodríguez, E. Silva, F. Blaabjerg, P. Wheeler, J. Clare, and J. Pontt, "Matrix converter controlled with the direct transfer function approach: analysis, modelling and simulation," International Journal of Electronics, vol. 92, no. 2, pp. 63-85, 2005.

[7] M. Jussila and H. Tuusa, "Comparison of direct and indirect matrix converters in induction motor drive," in Proceedings of the 32nd Annual Conference on IEEE Industrial Electronics (IECON '06), pp. 1621-1626, Paris, France, November 2006.

[8] H. W. van der Broeck, H. Ch. Skudelny, and G. V. Stanke, "Analysis and realization of a pulse width modulator based on voltage space vectors," IEEE Transactions on Industry Applications, vol. 24, no. 1, pp. 142-150, 1988. 

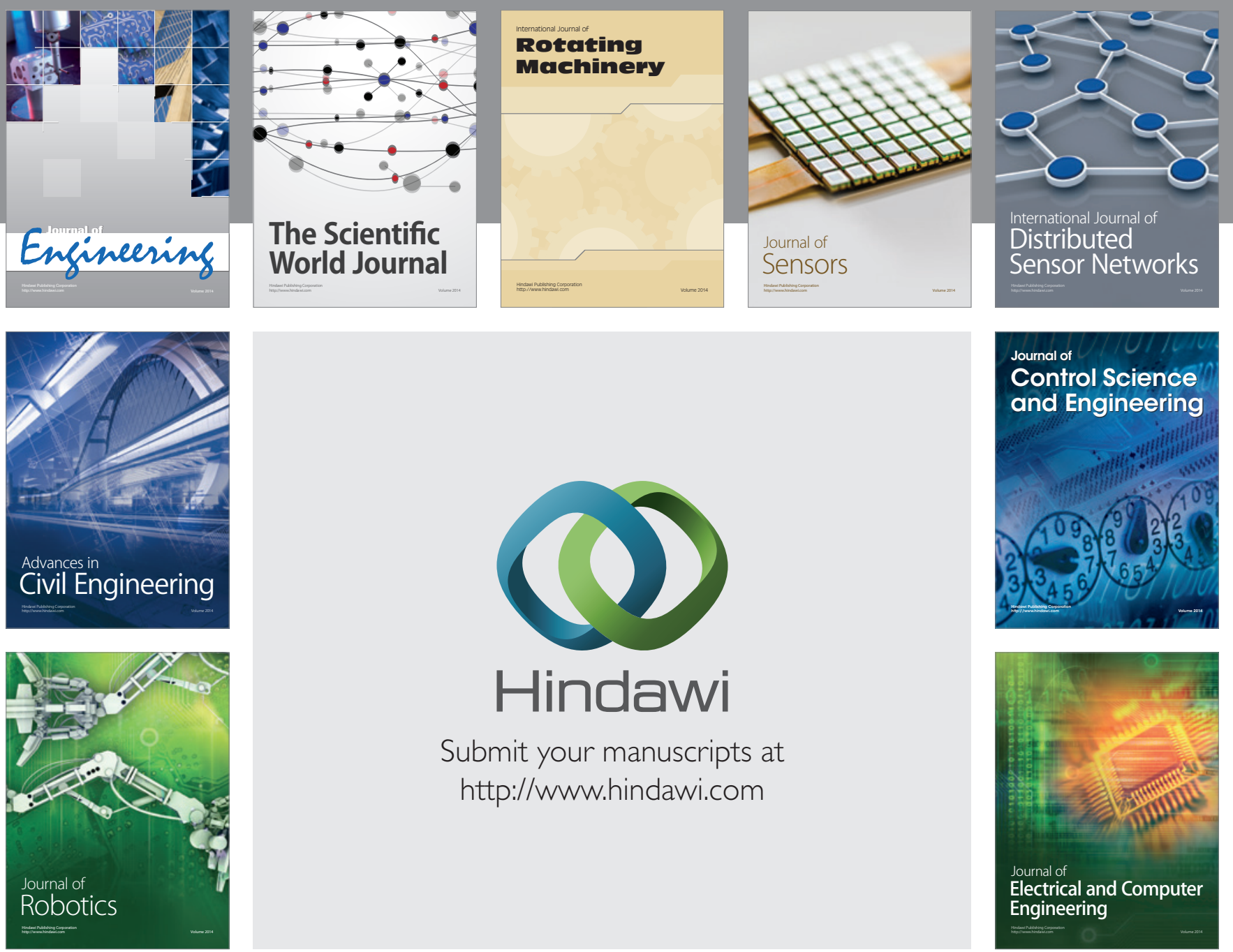

Submit your manuscripts at

http://www.hindawi.com
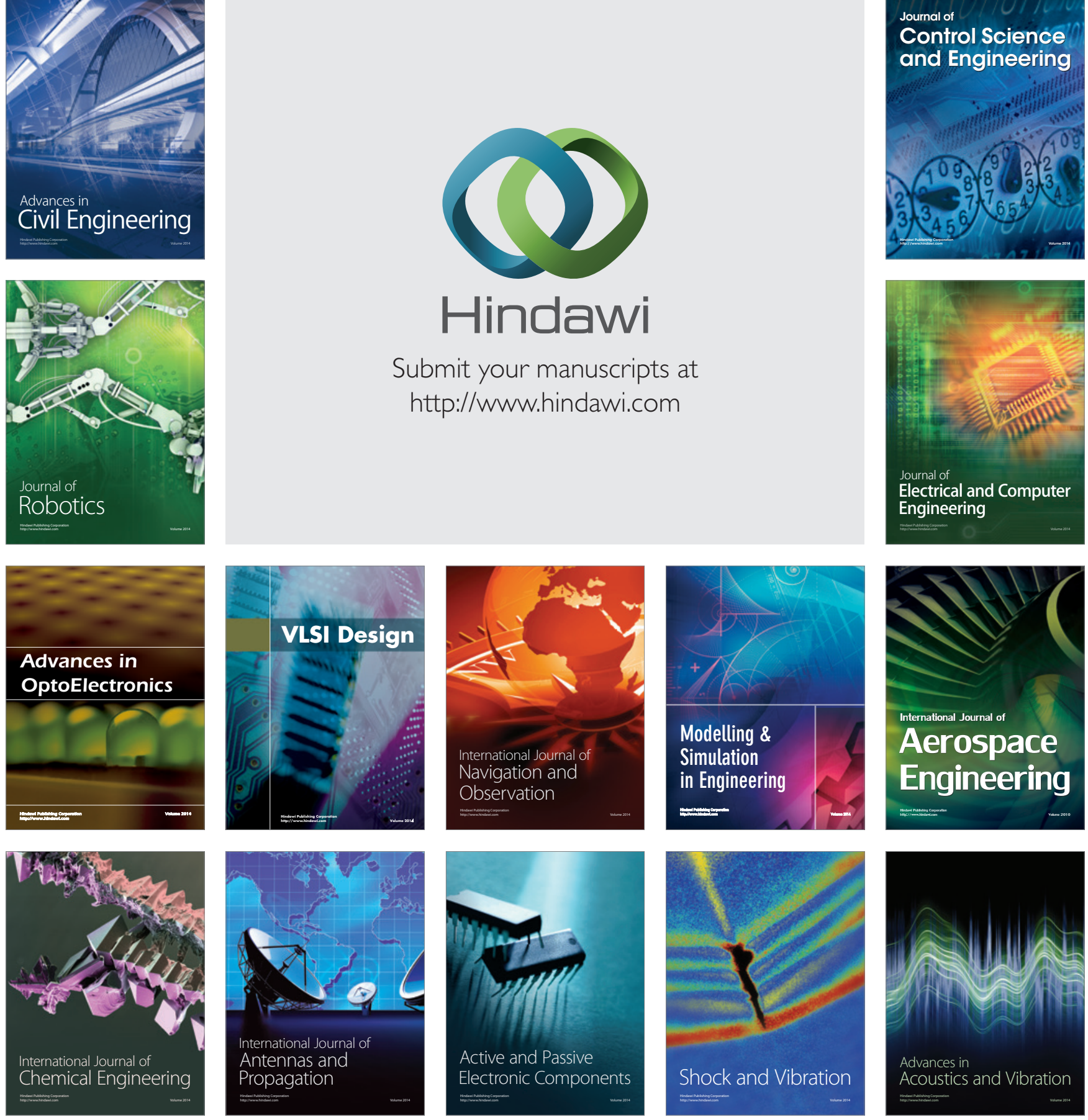